\title{
Razmerje med sektorsko regulacijo in konkurenčnim pravom pri regulaciji elektronskih komunikacij
}

UDK: $343.533: 004.9: 659.2$

\author{
Tanja Muha \\ Agencija za pošto in elektronske komunikacije RS \\ tanja.muha@apek.si
}

\begin{abstract}
IZVLEČEK
Ob spoznanju, da pravila konkurenčnega prava ne morejo odgovoriti na izzive, ki se pojavljajo na področju elektronskih komunikacij, ter z začetki liberalizacije trga elektornskih komunikacij, je bil na ravni Evropske unije vzpostavljen harmoniziran regulatorni okvir, ki predstavlja temelj za ustanovitev nacionalnih regulatornih organov, ki naj bi ta okvir izvajali in ga nadzorovali. Regulatorno poseganje na trg mora biti natančno, jasno in predvsem učinkovito. Vprašanje, ki se pojavlja in ga je treba v luči razvoja regulatornega okvira vsaj upoštevatii, je vprašanje doseganja in spoštovanja teh načel v primeru, ko se uporabljajo tako pravila sektorske regulacije kot splošna pravila konkurenčnega prava. $\mathbf{v}$ članku predstavljamo, kako pogosto prihaja do vsebinskih in postopkovnih prekrivanj med nalogami nacionalnih regulatornih organov in nacionalnih organov za varovanje konkurence.
\end{abstract}

Ključne besede: elektronske komunikacije, konkurenčno pravo, sektorska regulacija, "ex-post" in "ex-ante" regulacija

\section{Razvoj sektorske regulacije}

Z razvojem liberalizacije določenih sektorjev ekonomije se je pojavilo tudi vprašanje samega administrativnega urejanja oz. nadzora nad spoštovanjem in izvajanjem pravil, ki so postala nujni sopotnik tega procesa. Ugotovljeno je bilo, da trg kot tak ne ponudi rešitve, ker ne delujejo temeljne ekonomske zakonitosti ponudbe in povpraševanja. Vzpostavitev pravno-regulatornega okvira seveda ni dovolj in ne more biti zadosten cilj, saj sama pravna pravila kaj hitro ostanejo mrtva črka na papirju.

Na podlagi navedenega in ob spoznanju, da pravila konkurenčnega prava, ki so del daljše tradicije pravnega urejanja gospodarskih razmerij na trgu in 
Tanja Muha

Razmerje med sektorsko regulacijo in konkurenčnim pravom pri regulaciji elektronskih komunikacij

delovanja le-tega, ne morejo odgovoriti na izzive, ki jih ponujajo določeni sektorji, so bili vzpostavljeni regulatorni okvir in regulatorni organi, ki naj bi ta okvir izvajali in ga nadzorovali.

Sektor elektronskih komunikacij ni v okviru navedenega nobena izjema in zato nikakor ne more biti presenečenje, da je sekundarna zakonodaja (3. člen Okvirne direktive') naložila državam članicam Evropske unije, naj vzpostavijo neodvisno regulatorno telo, ki bo nadzorovalo izvajanje sprejetih pravil in bo predvsem skrbelo, da ne bi prihajalo do anomalij na trgu.

Glede spremljanja stanja na trgu in vplivanja na morebitne prepovedane poslovne prakse na trgu se torej na področju elektronskih komunikacij srečujemo z dvema sklopoma pravnih pravil in sicer: (i) konkurenčno-pravna pravila in (ii) pravila sektorske regulacije.

Prva skupina pravil je bila oblikovana zaradi generalnega urejanja stanja na trgu in obravnava oz. skuša preprečiti predvsem naslednje prakse: (i) sklepanje protikonkurenčnih sporazumov, katerih namen ali učinek je omejevanje konkurence na določenem upoštevnem trgu ${ }^{2}$, (ii) zlorabo prevladujočega položaja na upoštevnem trgu oz. v ekonomskem kontekstu zlorabo pomembne tržne moči na upoštevnem $\operatorname{trgu}^{\mathbf{3}}$ in (iii) strukturne spremembe, katerih učinek utegne negativno vplivati na stanje konkurence na trgu in lahko $v$ nekem časovnem obdobju vodi do potencialnih težav $v$ obliki prej navedenih praks ${ }^{4}$.

Druga skupina pravil je bila oblikovana precej drugače in z drugim namenom. Temeljno vodilo sektorske regulacije oz. pravnih pravil, ki jo sestavljajo, je odstranitev morebitnih vstopnih ovir na trg, s čimer naj bi se vzpostavilo stanje na trgu, ki bi samo po sebi omogočalo razvoj konkurence. Seveda so pravila sektorske regulacije pomembna tudi z vidika oblikovanja drugih elementov, ki pa so pomemben sestavni del izvajanja nalog sektorskih regulatorjev (npr. določitev pristojnosti cenovne regulacije, podeljevanje številskega prostora itd.).

1 Direktiva Evropskega parlamenta in Sveta 2002/21/ES z dne 7. marec 2002 o skupnem regulatovnem okviru za elektronska komunikacijska omrežja in storitve (OJ L 108, str. 33-50). 2 Navedeno vprašanje ureja na nacionalni ravni Zakon o preprečevanju omejevanja konkurence in na ravni EU primarno Pogodba o ustanovitvi Evropske skupnosti (81. člen).

3 Navedeno vprašanje ureja na nacionalni ravni Zakon o preprečevanju omejevanja konkurence in na ravni EU primarno Pogodba o ustanovitvi Evropske skupnosti (82. člen).

4 Navedeno vprašanje ureja na nacionalni ravni Zakon o preprečevanju omejevanja konkurence in na ravni EU primarno Uredba o koncentracijah ter podrejeno Pogodba o ustanovitvi Evropske skupnosti (82. člen). 


\section{Temeljni cilji sektorske regulacije}

Da bi lažje analizirali razmerje sektorske regulacije in pravil konkurenčnega prava, moramo pogledati sam razvoj obeh skupin pravil ter predvsem cilje, ki jih posamezna pravila zasledujejo. Ker je predmet tega članka analiza sektorske regulacije $\vee$ Republiki Sloveniji in primerjalno $v$ nekaterih državah članicah na konkretnem primeru, se bomo podrobneje lotili le analize ciljev sektorske regulacije. Hkrati bomo, ko bo to potrebno zaradi lažjega razumevanja, poskušali analizirati tudi nekatere vidike konkurenčnega prava, ki pomembno vplivajo na samo uporabo teh pravil in njihovo sobivanje $v$ razmerju do sektorskih pravil.

\subsection{Razvoj učinkovite konkurence}

Na začetku moramo poudariti, da konkurenca sama po sebi ni cilj sektorske regulacije, ampak gre za pomemben, če ne celo vitalen instrument, s katerim lahko sektorski regulatorni organ vpliva na oblikovanje poslovne politike predvsem nacionalnega (vodilnega) telekomunikacijskega operaterja, saj gre načeloma za podjetje, ki ni učinkovito, ki ne ravna gospodarno in kjer je predvsem miselnost zaposlenih še vedno neprimerna za uspešno poslovanje $v$ pogojih tržne ekonomije. Organ s svojim poseganjem na trgu lahko ustvari pogoje za odstranitev ovir za vstop na trg.

Da bi dosegli razvoj ustrezne ponudbe, kar je najučinkoviteje mogoče doseči s pomembnim pritiskom na ponudbeni strani, morajo nacionalni regulatorni organi s svojimi ukrepi zagotoviti, da bo operater omrežja (npr. operater s pomembno tržno močjo na trgu dostopa do razvezave krajevne zanke) omogočil dostop drugim ponudnikom, da bodo odstranjene predvsem pravne (regulatorne) ovire za dostop in bodo ponudniki ravnali $v$ skladu $s$ povpraševanjem na trgu.

\subsection{Upoštevanje specifičnosti in značilnosti sektorja}

Sektor elektronskih komunikacij je prav gotovo eden tistih sektorjev ekonomije, ki ima svoje individualne značilnosti (npr. visoki potopljeni stroški povezani z izgradnjo omrežja), kljub temu pa odraža tudi temeljne zakonitosti trga kot takega.

V zvezi z navedenim je izrednega pomena, da regulatorni okvir, predvsem pa njegovo izvajanje, zagotovi, da bodo upoštevane tiste značilnosti, ki bistveno 
Tanja Muha

Razmerje med sektorsko regulacijo in konkurenčnim pravom pri regulaciji elektronskih komunikacij

prispevajo k ukrepom, ki jih nacionalni regulatorni organi sprejemajo, hkrati pa ne pomenijo bistvenega posega $v$ poslovno politiko subjektov na trgu ter pretiranega in nepotrebnega administrativnega bremena pri nastopanju na trgu.

Namen teh ukrepov je, da naj bi liberalizacija zmanjševala obseg sektorske regulacije in dejansko vodila sektor pod "okrilje " pravil konkurenčnega prava, ki so oblikovana zato, da varujejo stanje konkurence na trgu (učinkovito konkurenco ${ }^{5}$.

\subsection{Učinkovito izvajanje regulatornih funkcij}

Nedvomno je mogoče že iz zgoraj navedenega ugotoviti, da je izvajanje regulatornih funkcij administrativni poseg državnega organa $\vee$ delovanje subjekta na trgu in je zato bistvenega pomena, da to poseganje ne gre dlje kot je nujno potrebno in se zagotovi izpolnjevanje določenih ciljev, predvsem delovanja trga.

Proces liberalizacije naj bi zagotovil, da se bo sektorska regulacija slej ko prej "poslovila" in da bodo tudi na področju elektronskih komunikacij intervenirali le konkurenčno-pravni organi.

Ali v Evropi in Evropski Uniji ter na enotnem evropskem trgu dejansko lahko govorimo o tem procesu, je težko ugotoviti. Trenutno objavljeni predlog Evropske komisije glede sprememb in dopolnitev regulatornega okvirja za področje elektronskih komunikacij nakazuje, da bodisi proces liberalizacije ni tako daleč kot se je v določenem trenutku zdelo, ali da smo bodisi priča pretiranemu poseganju regulatornih organov na delovanje na trgu.

$\checkmark$ tem trenutku je mogoče ugotoviti, da gre prav gotovo za skupek obeh elementov, pri čemer pa se vseeno zdi, da prevladuje prvi. Dejansko je mogoče ugotoviti, da Evropska komisija poskuša omejiti sektorsko regulacijo predvsem na tista področja, ki so se zares izkazala za najbolj problematična ter hkrati zanimiva za vstopajočo konkurenco (npr. širokopasovni dostop do interneta).

5 Pomembno je poudariti, da je cilj konkurenčnega prava učinkovita konkurenca in ne popolna konkurenca, kot se pogosto uporablja v laični javnosti. Pojem popolne konkurence je le postulat in ideja, saj dejansko takega stana na trgu razen v teoriji ni mogoče doseči. 


\section{Administrativno poseganje na stanje na trgu}

Ob upoštevanju spoznanj ekonomske teorije, da poseganje države na stanje na trgu ni zaželeno ali primerno, je treba poudariti, da mora biti regulatorno poseganje na trg natančno, jasno in predvsem učinkovito. To so temeljni postulati in načela regulacije, ki veljajo ne le za sektor elektronskih komunikacij, temveč tudi za druga področja, kjer nastopajo nacionalni regulatorni organi.

Vprašanje, ki se pojavlja in ga je treba v luči razvoja regulatornega okvira vsaj upoštevati, če ne tudi čim prej in čim bolj učinkovito tudi rešiti, je vprašanje doseganja in spoštovanja zgoraj navedenih načel v primeru, ko se uporabljajo tako pravila sektorske regulacije kot splošna pravila konkurenčnega prava.

Načelo good regulatory governance, ki ga zasleduje Evropska komisija pri oblikovanju posameznih sektorskih politik, naj bi bilo spoštovano tudi na področju elektronskih komunikacij. In načeloma je temu ob hitrem vpogledu $v$ pravna pravila celo mogoče pritrditi. Nacionalni konkurenčni organi uporabljajo pravila konkurenčnega prava (npr. Zakon o preprečevanju omejevanja konkurence; $v$ nadaljevanju ZPOmK), medtem ko nacionalni regulatorni organi uporabljajo pravila sektorske regulacije (npr. Zakon o elektronskih komunikacijah). Hkrati gre v prvem primeru za intervencijo na ex post osnovi, medtem ko nacionalni konkurenčni organi nastopajo na trgu na ex ante osnovi. $\checkmark$ določenih primerih je celo jasno, da lahko ukrepajo le nacionalni konkurenčni organi (npr. področje koncentracij). Vendar, ali je temu res tako?

$\checkmark$ nadaljevanju bomo videli, da na področju, ki ga obravnava ta članek, prihaja do vsebinskih in postopkovnih prekrivanj med nalogami nacionalnih regulatornih organov in nacionalnih organov za varovanje konkurence.

Dejansko z razvojem določenih pravil ni več mogoče govoriti o jasni razmejitvi med konkurenčnim pravom in pravili sektorske regulacije. Prvi argument, ki govori v prid nejasni razmejitvi, je naraščajoča konvergenca pravil konkurenčnega prava in pravil sektorske regulacije. Kaj to pomeni? Gre dejansko za razvoj, ko lahko predvsem na področju elektronskih komunikacij govorimo o uporabi konceptov konkurenčnega prava $v$ sektorski regulaciji (npr. koncept operaterja s pomembno tržno močjo). Vendar ne gre za razvoj, ki bi šel le $v$ smeri konkurenčnega prava nasproti sektorski regulaciji.

V okviru konkurenčnega prava vedno večkrat ugotavljamo, kako se ravnajo sektorski regulatorji pri svojem delu. Tipičen primer tega je uporaba ukrepa obveznosti medomrežnega povezovanja, ki je eden od temeljnih 
Tanja Muha

Razmerje med sektorsko regulacijo in konkurenčnim pravom pri regulaciji elektronskih komunikacij

ukrepov, s katerim nacionalni regulatorni organi zagotavljajo, da vstopajoči na trg lahko dostopajo do končnih uporabnikov pri uporabi infrastrukture operaterja s pomembno tržno močjo. Hkrati pa se $v$ okviru konkurenčnega prava razvija t.i. teorija bistvene dobrine ${ }^{\boldsymbol{6}}, \mathrm{v}$ okviru katere se postavlja vprašanje, ali je podjetje $\mathrm{s}$ prevladujočim položajem na trgu upravičeno zavrniti dostop do svojega omrežja, še posebej v primeru, ko se izkaže, da gre za bistveni element, katerega odsotnost pomeni nezmožnost delovanja in nastopanja na trgu.

Hkrati se pristojnosti nacionalnih regulatornih organov razvijajo tako, da rešujejo pritožbe in spore, ki po svoji vsebini posegajo na področje konkurenčnega prava ter so tradicionalno del pristojnosti $\vee$ okviru splošne regulacije stanja konkurence na trgu.

\subsection{Vsebinsko prekrivanje}

Kot že omenjeno, se $v$ okviru izvajanja pristojnosti nacionalnih regulatornih organov srečujemo $z$ vprašanji, ki po svoji naravi bodisi spadajo $v$ konkurenčno pravo, bodisi jim $\vee$ okviru slednjega lahko najdemo vsebinsko podobne primere.

Tipičen primer tega je regulacija dostopa do elektronskega komunikacijskega omrežja. V okviru Direktive o dostopu ${ }^{7}$ (9., 10. in 13. člen) najdemo več ukrepov, ki jih lahko nacionalni regulatorni organi naložijo operaterju $s$ pomembno tržno močjo če ugotovijo, da je dostop do njihovega omrežja bistvenega pomena za razvoj konkurence (npr. dostop do javnega telefonskega omrežja na fiksni lokaciji ali dostop do javnega mobilnega telefonskega omrežja).

Obenem se $v$ okviru konkurenčnega prava razvija t.i. teorija bistvene dobrine, ki v okviru ugotovljenih zlorab prevladujočega položaja zaradi zavračanja dostopa do neke bistvene dobrine, nalaga imetniku oz. lastniku te dobrine, da zagotovi dostop do nje.

Prav gotovo bi lahko sklepali, da gre po vsebini za zelo podobni zadevi, kar bi bilo mogoče prerekati oz. trditi, da so pravila konkurenčnega prava (predvsem zaradi sodne prakse) nekoliko bolj jasna in stroga ter dopuščajo veliko

6 Ali lahko res govorimo o teoriji bistvene dobrine, je zelo težko povedati. Čeprav se pojem uporablja, pa je njegova uporaba omejena predvsem na akademsko sfero. Dejstvo je, da je tudi ameriško Vrhovno sodišče $v$ zadevi Trinko na neki način odstopilo od tega pojma (essential facility) in razlaga navedeno zlorabo skozi določbo 2. člena Sherman Acta (ekvivalent 82. členu PES).

7 Direktiva Evropskega parlamenta in Sveta 2002/19/ES z dne 7. marec 2002 o dostopu do elektronskih komunikacijakih omrežij in pripadajočih naprav ter o njihovem medmrežnem povezovanju (OJ L 108, str. 7-20). 
manj manevrskega prostora Evropski komisiji pri sprejemanju odločitev na podlagi Uredbe $1 / 2003^{\boldsymbol{s}}$.

$\checkmark$ okviru regulacije dostopa do določenega omrežja je treba na tem mestu poudariti značilnost oz. bistveno razliko med sektorsko regulacijo in pravili konkurenčnega prava. Slednja namreč niso preveč primerna za cenovno regulacijo, saj le-ta zahteva veliko naknadnih aktivnosti pri spremljanju cenovne politike določenega subjekta na trgu in sam nadzor nad izvajanjem naloženih obveznosti. S tega vidika, čeprav prihaja do prekrivanja glede možnosti izvajanja te funkcije, je sektorski regulator $v$ okviru svojega poznavanja sektorja $\vee$ veliko boljšem položaju kot konkurenčni organ, prav tako pa ima na voljo več in učinkovitejše instrumente nadzora.

$\checkmark$ zadnjem času ugotavljamo tudi določene posebnosti v razvoju sektorske regulacije z vidika upoštevanja drugih politik (npr. varovanje okolja). Čeprav so možnosti sektorskega regulatorja širše, predvsem ima slednji več diskrecije, pa prihaja tudi v okviru uporabe pravil konkurenčnega prava do vedno večje vloge nekaterih drugih politik (npr. $v$ okviru 81. člena PES ${ }^{\boldsymbol{9}}$ - kolektivne pogodbe niso upoštevane kot pogodbe, ki bi lahko bile prepovedane $\vee$ okviru tega člena, čeprav mogoče tudi vplivajo na konkurenco na trgu).

\subsection{Prekrivanje pristojnosti}

Nacionalni regulatorni organi imajo vedno več pristojnosti $\vee$ okviru reševanja raznih medoperaterskih ali medpotrošniških sporov. Ne glede na izvajanje te funkcije pa $\vee$ praksi lahko pride do situacije, ko je neki spor lahko tudi predmet postopka pred nacionalnim konkurenčnim organom (npr. $\vee$ okviru presoje nekega sporazuma z vidika prepovedi v 81. členu PES).

Zelo zanimivo področje, kjer prihaja do potencialnega prekrivanja pristojnosti, je možnost nalaganja denarnih kazni. $\vee$ okviru izvajanja slednje funkcije ima tako npr. nacionalni regulatorni organ kot prekrškovni organ pravico in dolžnost, da $v$ primeru ugotovljenih kršitev ZEK-oma kršitelju poleg naloženega ukrepa $v$ postopku nadzora naloži tudi plačilo globe.

8 Uredba Sveta (ES) št. 1/2003 z dne 16.decembra 2002 o izvajanju pravil konkurence iz členov 81 in 82 Pogodbe (OJ L 1, str. 1)

9 Pogodba o ustanovitvi Evropske skupnosti (konsolidiran tekst dostopen na: http://eurlex.europa. Eu/en/treaties/dat/12002E/pdf/12002E EN.pdf) 
Tanja Muha

Razmerje med sektorsko regulacijo in konkurenčnim pravom pri regulaciji elektronskih komunikacij

Hkrati pa ima nacionalni konkurenčni organ pravico in dolžnost, da po ZPOmK naloži globo $v$ primeru, da je določeni subjekt kršil pravila konkurenčnega prava.

$\checkmark$ primeru, da bi oba organa ugotovila kršitev materialnih zakonov $z$ istim dejanjem, bi oba organa lahko naložila plačilo globe, saj gre za dve različni materialni podlagi in torej načeloma ne moremo uporabiti pravila ne bis in idem ${ }^{\mathbf{1 0}}$.

\section{Potencialna nevarnost regulatornih konfliktov}

Ne glede na očitno podobnost materialnih vsebin oz. pravil sektorske regulacije in konkurenčnega prava lahko pride do konflikta $v$ odločitvah obeh organov. Kot primer slednjega lahko navedemo odločbi Evropske komisije na področju elektronskih komunikacij in sicer v primeru Deutsche Telecom (2003) in v primeru Telefonica (2007).

$\checkmark$ obeh primerih sta pristojna nacionalna regulatorna organa dala soglasje $\mathrm{k}$ cenam veleprodajnih storitev na trgu širokopasovnega dostopa do interneta in hkrati nista nasprotovala cenam maloprodajnih storitev. $V$ obeh primerih je Evropska komisija ugotovila, da sta nacionalna telekomunikacijska operaterja zlorabila prevladujoč položaj na trgu širokopasovnega dostopa do interneta $s$ tem, da sta s postavljanjem (pre)visokih veleprodajnih cen in (pre)nizkin maloprodajnih cen s politiko škarij cen onemogočila razvoj konkurence.

Evropska komisija je $v$ obeh primerih izdala odločbo na podlagi 86(3). člena PES, pri čemer pa se upravičeno postavlja vprašanje, ali ne bi morala Evropska komisija dejansko ukrepati proti državi članici, ker nacionalni regulatorni organ ni zagotovil, da bi cene veleprodajnih storitev odražale stroškovno ceno te storitve in bi cena maloprodajnih storitev ne bila rezultat politike roparskih cen oz. politike škarij cen. Nekoliko drugačna pa kljub temu konfliktna situacija bi se lahko pojavila $v$ primeru reševanja vprašanja dostopa do elektronskega komunikacijskega omrežja. Medtem ko je ukrep dostopa $\vee$ okviru določbe 12. člena okvirne direktive $v$ popolni diskreciji nacionalnega regulatornega organa, ki na podlagi presoje stanja na trgu po navadi naloži ta ukrep, v kolikor ugotovi, da je na določenem trgu stanje tako, da ima neki operater položaj operaterja $s$ pomembno tržno močjo.

10 Gre za eno temeljnih načel kazenskega prava katerega temeljna vsebina je, da nekdo ne more dvakrat biti obsojen za isto kaznivo dejanje. 
Razmerje med sektorsko regulacijo in konkurenčnim pravom pri regulaciji elektronskih komunikacij

Hkrati pa bi nacionalni konkurenčni organ $\vee$ primeru reševanje pritožbe podjetja, ki mu lastnik omrežja ni dovolil dostop do tega omrežja, moral presojati kriterije v primeru Brönner. Kot je mogoče ugotoviti iz prakse Evropske komisije, slednja le $v$ redkih, izjemnih primerih tudi dejansko ugotavlja, ali so vsi kriteriji iz tega primera izpolnjeni in je zato treba podjetju naložiti ukrep dopustitve dostopa do t.i. bistvene dobrine.

Tabela 1: Primerjava uporabe pravil sektorske regulacije in konkurenčnega prava

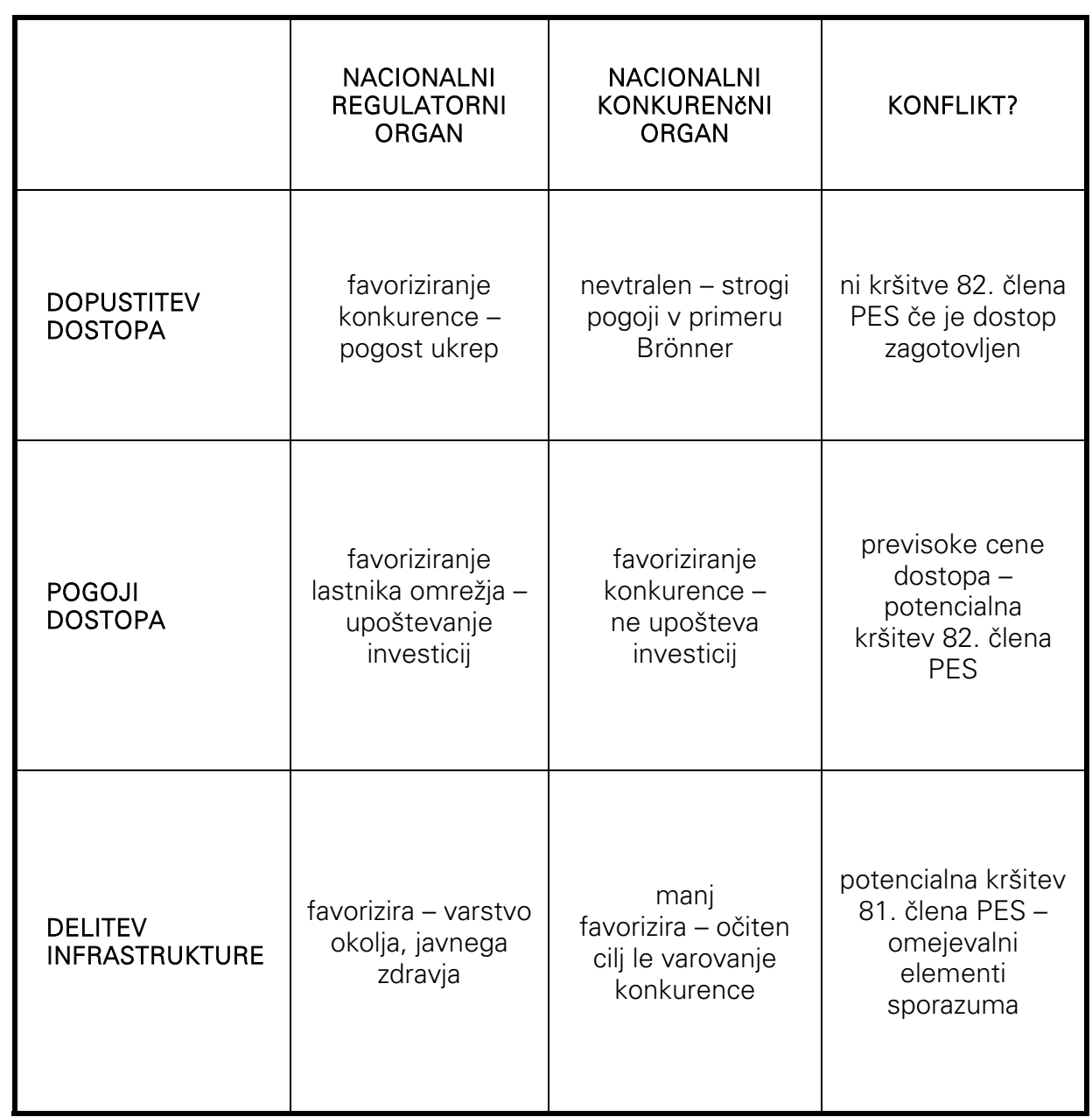

Vir: Lasten prikaz na podlagi literature 
Tanja Muha

Razmerje med sektorsko regulacijo in konkurenčnim

pravom pri regulaciji elektronskih komunikacij

Navedena nekonsistentna regulatorna praksa ima lahko torej precej negativnih učinkov. Slednje bi lahko razdelili v naslednje skupine:

- negativni in nejasno signali industriji glede možnosti vstopa na upoštevni trg in uporabo različnih regulatornih pravil;

- potencialno negativni vplivi na investicije $\vee$ sektorju zaradi regulatornih nejasnosti in nedoslednosti;

- $\quad$ potencialni razvoj t.i. forum shoppinga (izbire pristojnosti glede na verjetnost pozitivne rešitve pritožbe).

Naslednja nejasnost in nedoslednost, ki se lahko pojavi in se odraža tudi v dveh zgoraj navedenih primerih, je problematika, ki izhaja iz načela, zapisanega $\checkmark$ sektorskem regulatornem okviru in sicer, da pravila slednjega oz. njihova uporaba ne onemogočajo nacionalnim konkurenčnim organom sprejemanja drugačne odločitve $v$ isti zadevi. Da bi bila zadeva še nekoliko bolj zanimiva oz. zapletena, je treba omeniti možnost pritožnikov, da se $v$ skladu z reformo konkurenčnega prava pritožijo tudi na nacionalno sodišče, saj sta tako 81. kot 82. člen PES neposredno učinkovita in ju nacionalno sodišče lahko uporabi oziroma celo mora uporabiti.

\section{Omejevanje regulatornih konfliktov}

Kot je mogoče ugotoviti iz zgoraj navedenega, pojav regulatornih konfliktov prav gotovo ne prispeva $\mathrm{k}$ preglednosti, jasnosti in pravni varnosti, ki jih vsak udeleženec na trgu (upravičeno) pričakuje. Zaradi tega je bistvenega pomena, da se tako nacionalni regulatorni organi kot tudi nacionalni konkurenčni organi zavedajo navedenih omejitev in jih tudi poskušajo odpraviti. $V$ nadaljevanju bomo pogledali nekatere aktivnosti oz. potencialne ukrepe, ki bi bili primeri za omejitev ali celo odpravo navedenih prekrivanj.

\subsection{Obveznost spremljanja pravil konkurenčnega prava}

Prav gotovo je mogoče pritrditi dejstvu, da so pristojnosti in naloge nacionalnih regulatornih organov jasno in nedvoumno določene $v$ sekundarni zakonodaji Evropske skupnosti, ki se kasneje uvaja v nacionalno zakonodajo (npr. 120. člen ZEKom). Čeprav je splošno pravilo, da nacionalni regulatorni organi nimajo pristojnosti uporabe pravil konkurenčnega prava, pa sama sekundarna 
zakonodaja (npr. 22(3). člen poštne direktive "1) ali praksa (npr. Ofcom) omogočata, da nacionalni regulatorni organi uporabljajo tudi pravila konkurenčnega prava.

Ne glede na navedeno pa slednje izhaja že iz splošnih pravil prava Skupnosti, ki nalaga vsem državnim organom, da pri svojem delu upoštevajo pravo Skupnosti. Slednje načelo je tudi jasno in nedvoumno izraženo $v$ odločbi Sodišča Evropskih skupnosti v primeru GB-Inno-BM, kjer je slednje jasno reklo da »države članice ne smejo, ne glede na dejstvo, da je 82. člen PES naslovljen na podjetja, sprejemati ali uveljavljati pravna pravila, ki bi onemogočila učinkovanje in učinkovitost pravil Skupnosti«.

Pri tem je pomembno, da pojem države članice ne gledamo ozko, ampak kot državo članico upoštevamo vsak subject, v zvezi s katerim ali na katerega ima predmetna država članica bistven vpliv.

Navedeno pravilo je bilo še jasneje in nedvoumno razvito $v$ primeru Italian Matches, kjer je Sodišče Evropskih skupnosti reklo da "obveznost neupoštevanja nacionalne zakonodaje, ki je $v$ nasprotju s pravnim redom Skupnosti, ne velja le za nacionalna sodišča, ampak tudi za druge organe državne uprave in javne uprave, katerih naloga je, da zagotovijo učinkovito in pravilno uporabo tega pravnega reda."

Ne glede na navedeno in ob upoštevanju splošnega pravila, da nacionalni konkurenčni organi niso nujno aktivni uporabniki pravil konkurenčnega prava, je treba ugotoviti, da je poznavanje slednjih bistvenega pomena za učinkovito ter pravilno uporabo same sektorske regulacije. Nedvoumno je namreč, da je predvsem trenutno veljavni regulatorni okvir za področje elektronskih komunikacij $\vee$ veliki meri oblikovan po načelih splošnega konkurenčnega prava in je zato bistvenega pomena, da nacionalni regulatorni organi poznajo ta pravila oz. se z njihovo vsebino ustrezno seznanijo.

\subsection{Posebni ukrepi za izogibanje regulatornih konfliktov}

Prav gotovo se ni mogoče $\vee$ določenih primerih izogniti situaciji, ko pritožnik vloži svojo pobudo (pritožbo) tako pri nacionalnem regulatornem organu kot nacionalnem organu za varstvo konkurence ali celo pri Evropski komisiji. Gre za povsem legitimno in legalno pravico pritožnika, ki verjetno z vložitvijo

11 Direktiva 97/67/ES kot je bila spremenjena in dopolnjena z Direktivo 2008/6/ES. 
Tanja Muha

Razmerje med sektorsko regulacijo in konkurenčnim pravom pri regulaciji elektronskih komunikacij

pobude na več naslovih poskuša, da bi vsaj kateri od teh organov tudi v resnici postopal v skladu z njegovimi pričakovanji.

Upoštevaje navedeno pa je vseeno treba posebno pozornost nameniti izogibanju podvajanj v reševanju določenih primerov, še posebej če je mogoče, glede na vsebino pravnega pravila, da bosta oba organa odločala podobno. Pri tem naj opozorimo, da je Evropska komisija na področju elektronskih komunikacij izdala posebno sporočilo $v$ zvezi z uporabo pravil konkurenčnega prava $v$ sektorju elektronskih komunikacij, $\vee$ katerem je kot temeljno načelo predstavila načelo lex specialis ${ }^{\mathbf{2}}$.

Bistvena prednost slednjega je $v$ tem, da je Evropska komisija mnenja, da naj se primer rešuje že na nacionalni ravni in zato sama v primeru, da nacionalni regulatorni organ ali nacionalni organ za varstvo konkurence že rešujeta primer, ne bo ukrepala. Slednje velja v vseh primerih, razen ko odločitev na nacionalni ravni ni sprejeta $\vee$ nekem doglednem časovnem okviru oz. ko pritožnik na nacionalni ravni nima učinkovitega pravnega varstva $v$ smislu začasnih odločb (odredb).

Tak pristop je seveda dobrodošel z več vidikov:

- prioriteta se dodeljuje organu, ki je dejansko specializiran za določen sektor in veliko bolje pozna njegovo delovanje;

- $\quad v$ primeru, da je treba izreči ukrepe, katerih učinkovitost je odvisna od nadzora nad izvajanjem teh ukrepov, so nacionalni regulatorni organi veliko bolj usposobljeni, da dejansko izvajajo nadzorne funkcije;

- Časovni okvir, v katerem morajo odločati nacionalni regulatorni organi, je veliko bolj strog in zagotavlja zato več pravne jasnosti in varnosti za akterje na trgu.

Ne glede na navedeno pa ima pravilo lex specialis tudi določene nejasnosti, saj Evropska komisija ni jasno odgovorila na vprašanje razmejitve pristojnosti med nacionalnimi regulatornimi organi in nacionalnimi organi za varstvo konkurence, ni definirala pojma izrednih okoliščin, ki dovoljujejo prevzem pristojnosti, in ni opredelila aktivnosti v primeru, da nacionalni regulatorni organ, kljub njihovi prisotnosti, ne analizira konkurenčno-pravnih vidikov zadeve.

12 Načelo lex specialis derogate lex generalis pomeni, da $v$ primeru posebnih pravil ta prevladajo nad splošnimi pravili. $V$ konkretnem primeru to pomeni, da pravila sektorske regulacije prevladajo nad pravili splošnega konkurenčnega prava, če seveda urejajo isto vprašanje. 
Tudi če upoštevamo te omejitve, je treba pogledati način, ki bi omogočil izogibanje dvojnim postopkom na nacionalni ravni. Čeprav ni jasna možnost uporabe pravila lex specialis, to še ne pomeni, da na voljo niso druga, prav tako učinkovita sredstva.

Eden najbolj priporočljivih načinov izogibanja regulatornih konfliktov je primerno sodelovanje pristojnih državnih organov. To pomeni, da v primeru, ko nacionalni regulatorni organ pri izvajanju svojih funkcij ugotovi, da se pojavljajo določena konkurenčno-pravna vprašanja oz. problemi, o tem obvesti nacionalni organ za varstvo konkurence. $\vee$ okviru sektorja elektronskih komunikacij je to delno že opredeljeno $v$ okviru postopka posvetovanja nacionalnih organov za varstvo konkurence pri analizi upoštevnega trga in posvetovanju urada za varstvo konkurence. Navedeno neformalno pravilo pa seveda velja tudi $v$ obratni smeri, kar pomeni, da tudi nacionalni organi za varstvo konkurence o določenih sektorskih vprašanjih obvestijo pristojni nacionalni regulatorni organ.

Sodelovanje državnih organov je praviloma prisotno tudi $v$ tistih državah članicah, kjer je dejansko prišlo do prenosa dela pristojnosti nacionalnih organov za varstvo konkurence na nacionalne regulatorne organe (npr. Ofcom, Postcomm). Obenem naj poudarimo, da je pravilo sodelovanja državnih organov del splošnega upravnega postopka, ki se po navadi uporablja tako $v$ primeru nacionalnih regulatornih organov kot tudi nacionalnih organov za varstvo konkurence.

\section{Izkušnje iz preteklosti in uporaba $v$ prihodnosti}

Kot je bilo mogoče videti do sedaj, dvojna pristojnost $v$ isti zadevi ni primeren niti učinkovit način regulacije in zato pomeni veliko tveganje pri zagotavljanju spoštovanja načel, ki smo jih opredelili v uvodu tega članka.

$\checkmark$ skladu $s$ tem pravna in regulatorna teorija predlagata dvojni pristop $k$ reševanju problematike:

- $\quad v$ primeru sektorske intervencije pravila konkurenčnega prava naj ne bi bila več (sploh) uporabljena;

- $\quad v$ primeru nejasne ali neučinkovite intervencije sektorske regulacije bi lahko Evropska komisija ukrepala proti sami državi članici in ne nujno vzpostavljala dodatno (dvojno) breme operaterju. 
Tanja Muha

Razmerje med sektorsko regulacijo in konkurenčnim

pravom pri regulaciji elektronskih komunikacij

\subsection{Sektorska intervencija - razlog za neuporabo kon- kurenčnega prava?}

Kot je bilo mogoče zaključiti iz zgoraj omenjenih primerov, se lahko zgodi, da odločitev nacionalnega regulatornega organa še ne zagotavlja operaterju, da ne bo $v$ prihodnosti subjekt postopka pristojnih konkurenčno-pravnih organov.

$\checkmark$ skladu s tem je torej vprašanje, ali lahko $v$ primeru prava Skupnosti uporabimo pravilo, ki je bilo razvito $\vee$ zadevi Trinko $\vee$ ZDA, kjer je Vrhovno sodišče reklo, da kadar so bile določenemu operaterju že naložene neke obveznosti $v$ okviru sektorske regulacije, pravila konkurenčnega prava naj ne bi bila uporabljena ${ }^{13}$.

Glavna ideja, ki je vodila Vrhovno sodišče pri sprejemu te odločitve, je bila, da bi bila intervencija konkurenčnega prava v primerih, ko je nekemu operaterju že naložena sektorska obveznost, omejenega značaja ter predvsem neučinkovita.

$\checkmark$ zvezi s samo možnostjo uporabe tega načela $v$ pravu Skupnosti je potrebno biti zelo previden. čeprav je Evropska komisija $\vee$ nekaterih primerih (npr. primer O2/T-Mobile) že nakazala, da ni pripravljena ukrepati $\vee$ okviru pristojnosti, ki so ji podeljene $\vee$ Uredbi 1/2003, v primeru, da so na voljo ukrepi sektorske regulacije, pa je treba tako rešitev analizirati skozi prizmo pravne tradicije in značilnosti kontinentalnega pravnega reda ter common-law sistema.

Dejansko se je v Evropski uniji že zgodilo, da nacionalni regulatorni organi bodisi niso dovolj učinkovito preprečevali določenih poslovnih praks, ki so imele negativen učinek na delovanje trga, bodisi niso dovolj učinkovito izvajali svojih nalog. $\vee$ takem primeru je Evropska komisija po navadi začela s široko analizo določenega sektorja (sector inquiry) zato, da bi nacionalne regulatorne organe opozorila na določene probleme. $V$ prvem primeru take široke analize je Evropska komisija izdala odločbi $v$ primeru Deutsche Telecom in France Telecom (Wanadoo), medtem ko je $v$ drugem takem primeru izdala Uredbo o roamingu ${ }^{\mathbf{1 4}}$ $s$ katero je določila regulatorne ukrepe $\vee$ zvezi s cenami uporabe storitev mobilne telefonije $\vee$ drugi državi članici.

Prav tako pa je treba ugotoviti, da so določene zgodovinske razlike $v$ pravnih redih Evropske unije in ZDA, ki narekujejo, da sodbo $v$ primeru Trinko

13 Sodba Vrhovnega sodišča ZDA dostopna na:

http://www.fcc.gov/ogc/documents/opinions/2004/02-682-011304.pdf.

14 Regulation (EC) No 717/2007 of the European Parliament and of the Council of 27 June

2007 on roaming on public mobile telephone networks within the Community and amending Directive 2002/21/EC 
beremo z veliko mero previdnosti ter ob upoštevanju omenjenih omejitvenih dejavnikov.

Vsekakor je z vidika trenutnega in prihodnjega (potencialnega) razvoja regulatornega okvira za področje elektronskih komunikacij mogoče najti zelo zanimiv primer, kjer bi se lahko pojavilo vprašanje smiselnosti in upravičenosti uporabe pravil konkurenčnega prava $\vee$ primeru intervencije sektorske regulacije.

Gre za primer t.i. funkcionalne ločitve, ki je v predlogu sprememb in dopolnitev predstavljen kot eden izmed možnih ukrepov, ki bi jih lahko nacionalni regulatorni organi naložili operaterju (operaterjem - joint dominance) $\mathrm{s}$ pomembno tržno močjo, kjer je to potrebno zaradi preglednosti in zagotovitve nediskriminacije. Vprašanje, ki se pojavi, je seveda ali bi naložitev takega ukrepa pomenila nemožnost ukrepanja Evropske komisije na podlagi 7. člena Uredbe 1/2003, ki slednji podeljuje možnost naložitve ravnalnega ali strukturnega ukrepa v primeru kršitev pravil konkurenčnega prava. Vsekakor gre za zanimivo vprašanje, kjer ni mogoče dati enega in edinega odgovora. Mogoče kot nekakšen indic se lahko uporabi eden redkih primerov v zgodovini Evropske Komisije, ko je bil $v$ končni odločbi omenjen strukturni ukrep (primeru Deutsche Post), pri čemer pa je subjekt odločbe sam predlagal, da bo ustanovil samostojni pravni subjekt, da bi ustrezno obravnaval in rešil probleme, ki jih je identificirala Evropska komisija.

\subsection{Ukrepanje zoper državo članico}

$\checkmark$ primeru izdane odločbe nacionalnih organov se seveda lahko zgodi (kar je $\vee$ reguliranih sektorjih) pogosta praksa, da se naslovniki teh odločb odločajo za uporabo pravnih sredstev.

$\checkmark$ takih primerih lahko pridemo do situacije, ko se $v$ postopku pred nacionalnim sodiščem pojavi vprašanje pravilne razlage neke določbe nacionalne zakonodaje, ki je dejansko uvedba določbe prava Skupnosti. $V$ takem primeru lahko nacionalno sodišče na Sodišče Evropskih skupnosti v okviru postopka po 234. členu PES (postopek predhodnega vprašanja) naslovi vprašanje razlage določene določbe sekundarne zakonodaje Skupnosti v luči nacionalne določbe.

Sodišče Evropskih skupnosti lahko poda razlago določene pravne norme, pri čemer je nacionalno sodišče na to razlago pravno vezano. Pri tem Sodišče Evropskih skupnosti ne rešuje in ne reši primera pred nacionalnim sodiščem, ampak le poda zavezujočo razlago neke pravne norme. Čeprav je s tem več kot 
Tanja Muha

Razmerje med sektorsko regulacijo in konkurenčnim pravom pri regulaciji elektronskih komunikacij

nedvoumno zagotovljena pravna pravilnost neke odločbe, pa je slednji postopek dolgotrajen in predvsem precej neprimeren za sektor kot so elektronske komunikacije, kjer se zadeve odvijajo veliko hitreje, kot pa sodišča dejansko rešujejo zadeve.

Obenem ima Evropska Komisija kot varuh PES možnost, da zoper državo članico, ki ne zagotavlja spoštovanja pravnega reda Skupnosti, sproži več postopkov. Za potrebe tega dela sta pomembna in zanimiva predvsem dva.

Prvi je postopek po 226. členu PES, ki ga Evropska Komisija sproži zoper državo članico, ki ne bi zagotavljala spoštovanja pravnega reda Skupnosti bodisi z uporabo določenih pravil Skupnosti bodisi z neuporabo teh pravil. V primeru, da bi Sodišče Evropskih skupnosti ugotovilo, da država članica dejansko krši pravni red Skupnosti, bi ji naložilo, da mora slednje $v$ nekem časovnem okviru odpraviti ( $v$ nadaljevanju tudi kot možnost denarne kazni). Zadevni postopek je prav tako precej dolgotrajen, pri čemer se velikokrat dejansko zgodi, da države članice odpravijo zatrjevano nepravilnost najkasneje $v$ trenutku, ko Evropska komisija vloži tožbo pred Sodiščem Evropskih skupnosti zaradi nespoštovanja prava Skupnosti.

Drugi postopek po 86. členu PES sproži Evropska komisija zoper podjetje, ki krši pravila Skupnosti. Po navadi gre za pravila konkurenčnega prava, in sicer uporabo 86. člena v povezavi z 82. členom PES. Dejstvo je namreč, da države članice $v$ več primerih zagotovijo nacionalnim telekomunikacijskim operaterjem določene ekskluzivne ali posebne pravice, ki te postavljajo $v$ ugodnejši položaj nasproti njihovim konkurentom na trgu (npr. primera GSM Italy ali GSM Spain) s čimer lahko pride ali je dejansko prišlo do zlorabe prevladujočega položaja.

\section{Zaključek}

Z razvojem pravil regulacije trga elektronskih komunikacij z namenom njegove liberalizacije ni več mogoče govoriti o jasni razmejitvi med konkurenčnim pravom in pravili sektorske regulacije. Zaradi naraščajoče konvergence med pravili konkurenčnega prava in pravili sektorske regulacije se $\vee$ okviru izvajanja pristojnosti nacionalnih regularonih organov srečujemo $s$ prekrivanjem pristojnosti obeh. Ne glede na očitno podobnost materialnih vsebin oziroma pravil sektorske regulacije in konkurenčnega prava pa lahko pride do konflikta $\vee$ odločitvah 


\section{Razmerje med sektorsko regulacijo in konkurenčnim} pravom pri regulaciji elektronskih komunikacij

obeh organov. Eden najbolj priporočljivih načinov izogibanja regulatornih konfliktov je primerno sodelovanje pristojnih državnih organov. Ob upoštevanju splošnega pravila, da nacionalni regulatorni organi niso nujno aktivni uporabniki pravil konkurenčnega prava, je poznavanje slednjih bistvenega pomena za učinkovito ter pravilno uporabo sektorske regulacije.

Tanja Muha je diplomirala na Ekonomski fakulteti v Ljubljani ter leta 2006 zaključila specialistični študij na Fakulteti za upravo v Ljubljani. Zaposlena je na Agenciji za pošto in elektronske komunikacije RS kot specialistka za regulacijo telekomunikacijskega trga.

\section{Literatura in viri}

1. Geradin, D. (2004): Remedies in network industries: EC Competition Law vs. Sector-Specific Regulation. Intersentia, Oxford.

2. Monti, G. (2007): EC Competition Law. Cambridge, New York.

3. Motta, M..(2004): Competition Policy - Theory and Practice. Cambridge, New York.

4. Donoghu E, R., Padilla, J.(2006): The Law and Economics of Article 82 EC. Hart Publishing, Oregon.

5. Gurpegui, I., Kordasiewicz, P.(2007): Solving problems at the source...Competition Policy Newsletter (Spring 2007).

6. Le Meur, J.Ch., Gurpegui, I., Viertio, K. (2007): Margin squeeze in the Spanish broadband market. Competition Policy Newsletter (Autumn 2007). 
Tanja Muha

Razmerje med sektorsko regulacijo in konkurenčnim

pravom pri regulaciji elektronskih komunikacij

SUMMARY

\section{THE RELATIONSHIP BETWEEN EX ANTE AND EX POST REGULATION - CASE OF ELECTRONIC COMIMUNICATIONS REGULATORY FRAMEWORK}

The purpose of the article is to identify sector-specific rules in electronic communication, their relationship to general competition law and to identify some potential areas of conflicts, proposing some valid and possible solutions.

The European Commission has identified that the sector of electronic communications does not deliver its benefits due to lack of competition on the relevant market. In order to avoid negative consequences and to stimulate the sector appropriate steps have been taken. The first step was the so called liberalization package, which enabled the full opening of the telecommunications market. However it has been established that this is not sufficient and that new solutions have to be laid down.

According to the principle of subsidiarity the European Commission proposed a new regulatory framework, which was adopted in 2002. Its main elements were based on the principles of competition law.

However the fact that national regulatory authorities started to use sector-specific legislation, which was largely based on competition law principles, led to the question how, if any, conflicts between these two sets of rules should be solved. It is obvious from the regulatory practice today that these conflicts indeed arise and can be put under the two larger groups: material (substance) and procedural conflicts.

It is clear that the purpose of the sector-specific (ex ante) regulation is to establish a level playing field for all market players and to remove all actual or potential barriers to entry. In order to achieve that, relevant competencies have been given to national regulatory authorities, which go beyond the competencies of the national competition authorities. Nevertheless there are still some overlaps, as for example in case of essential facility doctrine and use of Article 82 of the EC Treaty and provisions on access to the network of the significant market player (Access Directive) or in case of behavioural/structural remedy in case of breach of Article 82 of the EC Treaty and the possibility to impose separate cost accounting obligation on significant market player (framework Directive). 
It is obvious in the electronic communications sector that national regulatory authorities have to be aware of the substance of the competition law rules. Principles as significant market power, the relevant market and barriers to entry are principles which have been identified long ago by the competition law. It is therefore vital that national regulatory authorities apply these rules in cases of market analysis that they have to undertake. Such principle has been also clearly laid down also in the jurisprudence of the ECJ (cases GB-Inno-BM and Italian Matches).

It is also vital that competent national authorities cooperate under the umbrella of administrative law and apply the principle of lex specialis. The latter implies that in case when sector regulator and national competition authority are dealing with the complaint the first should take it over, due to its sector knowledge and awareness and due to the fact that competition authorities usually do not have at their disposal the right instruments to supervise (monitor) application of the imposed remedies.

However it should be emphasized that even though it has been mentioned that this principle can/should be applied, the situation is not as clear as one might want it to be. The fact remains that some principles (e.g. extraordinary circumstances) are not clearly defined; it is also not clear what happens if national regulatory authority does not take into account the competition law.

The easiest way to solve the problem is a close cooperation of the two authorities and maybe even a clear memorandum of understanding and cooperation (e.g. UK).

One of the questions that has been discussed in this article is the question of the objective justification of competition law intervention after the sector-specific actions already took place. There is no decisive answer to this question, but it should be emphasized that even though US Supreme Court indicated in Trinko that the application of sector-specific regulation prevents competition law actions, this principle should not be applied in European Union without looking at the facts of the case. Rather to the contrary, many signs show that in the Community law this principle would not apply (e. g. cases Deutsche Telecom and Wanadoo). 